\title{
ANALISI FAKTOR YANG BERHUBUNGAN DENGAN KEJADIAN INSOMNIA PADA WANITA MENOPAUSE DI POSYANDU WILAYAH KERJA PUSKESMAS PUNTI KAYU TAHUN 2021
}

\author{
Rima Syafaria ${ }^{1}$, Titin Dewi Sartika ${ }^{2}$, Turiyani ${ }^{3}$, H. Hazairin Efendi ${ }^{4}$ \\ Mashasiswa Universitas Kader Bangsa Palembang ${ }^{1}$ \\ Dosen Universitas Kader Bangsa Palembang ${ }^{234}$ \\ Email: ${ }^{2}$ titin_dewi@yahoo.com
}

\begin{abstract}
Menopausal women will experience several problems, one of which is sleep disorders (Insomnia). Insomnia is characterized by difficulty in initiating sleep. Various factors are thought to have a significant relationship with the occurrence of insomnia in postmenopausal women, including response to disease, lifestyle and anxiety levels. The purpose of this study was to determine the factors associated with the incidence of insomnia in postmenopausal women at the Posyandu in the Punti Kayu Palembang Health Centre in 2021. The research method used a survey Analytical by using design cross sectional, the sampling of this research used total sampling technique with a total sample of 63 people. Collecting data using a questionnaire sheet. The analysis used is analysis univariate and bivariat eusing testchi-square. The univariate results showed that 37 (58.7\%) menopausal women experienced insomnia, 27 (42.9\%) menopausal women, 27 (42.9\%) postmenopausal women, and $33(52.4 \%)$ menopausal women experienced poor lifestyle. anxiety as many as 30 (47.6\%) postmenopausal women. ResultsIt is known that there is a relationship between response to disease and the incidence of insomnia in postmenopausal women with ( $p$ value $=0.000)$, there is a relationship between lifestyle and the incidence of insomnia in menopausal women with $(p$ value $=0.000)$, there is a relationship between anxiety levels and the incidence of insomnia in menopausal women with ( $p$ value $=0.003$ ). The conclusion of this study is that there is a relationship between response to disease, lifestyle, anxiety levels with the incidence of insomnia in postmenopausal women at the Posyandu in the Punti Kayu Health Centre in 2021. This study is expected to encourage postmenopausal women to maintain their health, change lifestyle habits and consume water, and reduce anxiety.
\end{abstract}

Keywords: Insomnia, Response to Disease, Lifestyle, Level Anxiety

\begin{abstract}
ABSTRAK
Wanita menopause akan mengalami beberapa masalah yang salah satunya adalah gangguan tidur (Insomnia). Insomnia ditandai dengan adanya gangguan sulit untuk memulai tidur. Berbagai faktor yang diduga memiliki hubungan signifikan dengan terjadinya insomnia pada wanita menopause, di antaranya respon terhadap penyakit, gaya hidup dan tingkat kecemasan. Tujuan Penelitian ini untuk mengetahui faktor-faktor yang berhubungan dengan kejadian insomnia pada wanita menopause di Posyandu wilayah Kerja Puskesmas Punti Kayu Palembang Tahun 2021. Metode penelitian menggunakan Survey Analitik dengan menggunakan desain cross sectional, pengambilan sampel penelitian ini menggunakan teknik total sampling dengan jumlah sampel sebanyak 63 orang. Pengumpulan data menggunakan lembar kuesioner. Analisa yang digunakan adalah analisis univariat dan bivariat menggunakan uji chi-Square. Hasil univariat didapatkan responden yang mengalami insomnia sebanyak 37 (58.7\%) wanita menopause, responden dengan respon terhadap penyakit yang sakit sebanyak 27 (42.9\%) wanita menopause, responden dengan gaya hidup tidak baik sebanyak $33(52.4 \%)$ wanita menopause dan responden yang mengalami cemas sebanyak $30(47.6 \%)$ wanita menopause. Hasil bivariat diketahui ada hubungan respon terhadap penyakit dengan kejadian insomnia pada wanita menopause dengan $(p$ value $=0.000)$, ada hubungan gaya hidup dengan kejadian insomnia pada wanita menopause dengan $(p$ value $=0.000)$, ada hubungan tingkat kecemasan dengan kejadian insomnia pada wanita menopause dengan $(p$ value $=0.003)$. Kesimpulan penelitian ini yaitu ada hubungan respon terhadap penyakit, gaya hidup, tingkat kecemasan dengan kejadian insomnia pada wanita menopause di Posyandu Wilayah Kerja Puskesmas Punti Kayu Tahun 2021. Penelitian ini diharapkan pada wanita menopause untuk menjaga kesehatannya, mengubah kebiasaan gaya hidup dan mengkonsumsi air putih, serta mengurangi kecemasan.
\end{abstract}

Kata kunci: Insomnia, Respon Terhadap Penyakit, Gaya Hidup, Tingkat Kecemasan 


\section{PENDAHULUAN}

Menopause berarti berhentinya siklus menstruasi untuk selamanya bagi wanita yang sebelumnya mengalami menstruasi setiap bulan, yang disebabkan oleh jumlah folikel yang mengalami atresia terus meningkat, sampai tidak tersedia lagi folikel, serta dalam 12 bulan terakhir mengalami amenorea, dan bukan disebabkan oleh keadaan patologis. Wanita menopause juga mengalami perubahan psikologis salah satunya adalah gangguan tidur (insomnia) (Imelda, 2017).

Insomnia merupakan salah satu bentuk gangguan pola tidur yang umum terjadi pada lanjut usia (lansia) dimana prevalensinya bertambah tinggi seiring meningkatnya usia seseorang (Amalia, 2019).

Menurut WHO di kawasan Asia Tenggara populasi lansia sebesar 8\% atau sekitar 142 juta jiwa. Pada tahun 2050 diperkirakan populasi lansia meningkat 3 kali lipat dari tahun ini. Pada tahun 2000 jumlah lansia sekitar 5,300,000 (7,4\%) dari total polulasi, sedangkan pada tahun 2010 jumlah lansia $24,000,000 \quad(9,77 \%)$ dari total populasi, dan tahun 2020 diperkirakan jumlah lansia mencapai $28,800,000(11,34 \%)$ dari total populasi.

Di Indonesia pada tahun 2016 tercatat sebanyak 22,6 juta lansia atau 8,75 persen penduduk dengan umur tengah 28 tahun. Diperkirakan pada tahun 2030, jumlah itu akan naik jadi 41 juta orang atau 13,82 persen penduduk dengan umur tengah 32 tahun (Badan Pusat Statistik, 2016). Di Indonesia terdapat 11 Provinsi dengan persentase lansia lebih dari $7 \%$. Provinsi Sumatera Barat salah satu Provinsi yang memiliki populasi lansia di Sumatera Barat mencapai angka 44.403 orang dengan jumlah populasi terbanyak dikota Padang dengan jumlah 28.896 (Badan Pusat Statistik, 2015).

Data Dinas Kesehatan Kota Palembang, Tahun 2018 berdasarkan kelompok umur 45-74 tahun jumlah laki-laki adalah 179.531 dan perempuan 185.661 orang. Sedangkan untuk kelompok umur lebih dari 65 tahun jumlah lakilaki 7.033 orang dan perempuan 11.665 orang jumlah penduduk (Dinkes Kota Palembang, 2018).

Berdasarkan data Wilayah Kerja Puskesmas Punti Kayu Palembang tahun 2018 Jumlah Perempuan usia 45-60 tahun berjumlah 3.402, pada tahun 2019 berjumlah 6.193, pada tahun 2020 berjumlah 3.147 dan pada tahun 2021 berjumlah 4.944 orang. Pada Tahun 2019 Usia Lanjut $>60$ tahun menurut Jenis Kelamin, jumlah laki-laki adalah 1.377 dan perempuan 1.645 orang jumlah penduduk. Pada Tahun 2020 usia >60 tahun jumlah laki-laki adalah 1.088 dan perempuan 1.329 orang jumlah penduduk (Profil Puskesmas Punti Kayu Palembang).

Wanita yang memasuki usia menopause mengalami kesulitan tidur, dikarenakan sejumlah faktor yang mempengaruhinya. Faktor tersebut diantaranya adalah tingkat hormon, masalah kesehatan, gaya hidup yang kurang sehat, serta ketegangan akan situasi yang dialami. Sejumlah faktor tersebutlah yang dapat menyebabkan perempuan usia menopause mengalami insomnia (Erwani, 2017).

Angka prevalensi insomnia di dunia pada lansia diperkirakan sebesar $13-47 \%$ dengan proporsi sekitar $50-70 \%$ terjadi pada usia di atas 65 tahun. Dari hasil penelitian The Gallup Organization prevalensi sulit tidur (insomnia) pada usia lanjut di Amerika adalah 36\% untuk laki-laki dan 54\% untuk perempuan. Di Indonesia, angka prevalensi insomnia pada lansia sekitar 67\% (Meida, 2018).

Berdasarkan penelitian yang dilakukan Lestario di RSUP Moehammad Hoesin Palembang tahun 2011, prevalensi insomnia ditempat tersebut sebesar 79,2\% dimana insomnia banyak terjadi pada perempuan $(22,7 \%)$ dari pada laki-laki $(18,2 \%)$. Berdasarkan penelitian yang dilakukan Meida Rarasta di Panti Werdha Bakti dan Tresna Werdha Teratai Palembang tahun 2014, prevalensi insomnia pada usia lanjut cukup tinggi yaitu sebesar $43,3 \%$ lebih banyak terjadi pada rentang usia 60-74 tahun dan lebih tinggi terjadi pada wanita dari pada laki-laki.

Perubahan endokrin-hormone yang terlibat dalam kehidupan wanita, terutama disebabkan oleh kehilangan fungsi ovarium yang meningkat. Perubahan yang dirasakan wanita tersebut salah satunya adalah mengalami gangguan tidur (insomnia). Hot flushes juga dapat menyebabkan perempuan terbangun dari tidur, selain itu kesulitan tidur dapat disebabkan karena rendahnya kadar serotin pada masa pre menopause. Kadar serotin dipengaruhi oleh kadar endofrin.

Menurut Kozier (2008) menyatakan bahwa faktor-faktor yang mempengaruhi tidur adalah faktor usia, lingkungan, kelelahan, gaya hidup, stres psikologis, alkohol, dan stimulan, diet, merokok, motivasi, sakit, dan medikasi. Kim dan 
Moritz (2011) meyatakan bahwa faktor yang menyebabkan gangguan pola tidur pada lansia yaitu faktor internal dan eksternal.

Faktor yang mempengaruhi insomnia pada lansia adalah kecemasan yang menyebabkan kesulitan memulai tidur, masuk tidur memerlukan waktu yang lebih dari 60 menit, timbulnya mimpi menakutkan dan mengalami kesukaran bangun di pagi hari, merasa kurang segar (Prayitno, 2014).

Gaya hidup lansia seperti kebiasaan merokok mengkonsumi minuman yang mengandung kafein dan kurangnya olahraga menyebabkan timbulnya kesulitan tidur pada lansia. Individu yang merokok memerlukan waktu dua kali lebih banyak untuk bisa tidur dan lebih sering terbangun dibandingkan dengan individu yang tidak merokok. Selain itu lansia lebih sensitif terhadap kopi, dimana mengkonsumsi kopi 2 gelas atau lebih akan menyebabkan penurunan dari total jumlah waktu tidur sebanyak 2 jam dan peningkatan jumlah waktu yang dibutuhkan untuk jatuh tidur, biasanya dihitung dalam menit (Rafknowledge, 2014).

Faktor-faktor yang berhubungan dengan kualitas tidur yang buruk tersebut dapat dijadikan acuan dalam pencegahan gangguan tidur pada lansia. Penatalaksanaan gangguan tidur pada lansia meliputi pencegahan primer, sekunder, dan tersier. Pencegahan primer adalah upaya untuk menghindari penyakit atau kondisi kesehatan tertentu. Pencegahan primer yang dapat dilakukan terhadap gangguan tidur lansia adalah dengan melakukan higiene tidur yang baik.

Pencegahan sekunder adalah deteksi dini dan pengobatan terhadap kondisi kesehatan yang merugikan, meliputi tindakan nonfarmakologi dan farmakologi (Nasiri dan Fahimzade, 2017). Pencegahan tersier dilakukan jika penyakit atau kondisi tertentu telah menyebabkan kerusakan pada individu. Tujuan rehabilitasi yang dilakukan, yaitu agar lansia dapat menikmati tidur yang berkualitas baik sampai akhir hayatnya.

Pengetahuan akan faktor-faktor yang berhubungan dengan kejadian insomnia pada wanita menopause dapat menjadi acuan dari berbagai kegiatan promosi kesehatan yang tercakup dalam pencegahan primer (Nasiri dan Fahimzade, 2017).

Saat dilakukan studi pendahuluan kepada 10 orang wanita menopause di Posyandu Wilayah Kerja Puskesmas Punti Kayu didapatkan 6 orang dari 10 wanita menopause mengatakan sering mengalami gejala insomnia. Mereka mengatakan pernah mengalami kesulitan tidur, meskipun Tabel 1 Distribusi Frekuensi Variabel Penelitian tingkat kesulitan tidur berbeda pada masingmasing individu. Mereka juga mengatakan kalau setiap hari sulit untuk tertidur lagi setlah terbangun di tengah malam.

Berdasarkan latar belakang diatas peneliti ingin melakukan penelitian tentang "Analisis Faktor yang Berhubungan dengan Kejadian Insomnia pada Wanita Menopause di Posyandu Wilayah Kerja Puskesmas Punti Kayu Palembang Tahun 2021"

\section{Tujuan}

Untuk mengetahui hubungan Respon Terhadap Penyakit, Gaya Hidup, dan Tingkat Kecemasan secara simultan dengan kejadian Insomnia pada Wanita Menopause di Posyandu Wilayah Kerja Puskesmas Punti Kayu Tahun 2021.

\section{METODE PENELITIAN}

Desain penelitian bersifat kuantitatif dengan menggunakan survey analitik dengan pendekatan cross sectional. Penelitian ini dilaksanakan di Posyandu Wilayah Kerja Puskesmas Punti Kayu Palembang pada bulan Agustus-September 2021. Populasi dalam penelitian ini adalah semua wanita menopause yang ada di posyandu wilayah kerja puskesmas punti kayu, yang berjumlah 63 orang. Pengambilan sampel penelitian ini menggunakan teknik total sampling. Instrumen penelitian berupa lembar kuesioner. Analisa data menggunakan analisa univariat dan analisa bivariat dengan uji statistik chi square.

\author{
HASIL PENELITIAN \\ Hasil Univariat
}




\begin{tabular}{llcc}
\hline Insomnia & Frekuensi & $\begin{array}{c}\text { Persentase } \\
(\boldsymbol{\%})\end{array}$ \\
\hline 1 & Insomnia & 37 & 58,7 \\
2 & Tidak Insomnia & 26 & 41,3 \\
& Respon Terhadap Penyakit & Frekuensi & Persentase (\%) \\
\hline 1 & Sakit & 27 & 42,9 \\
2 & Tidak Sakit & 36 & 57,1 \\
& $\quad$ Gaya Hidup & Frekuensi & Persentase (\%) \\
\hline 1 & Tidak baik & 33 & 52,4 \\
2 & Baik & 30 & 47,6 \\
\hline & Tingkat Kecemasan & $\mathbf{f}$ & $\mathbf{\%}$ \\
\hline 1 & Cemas & 30 & 47,6 \\
\hline 2 & Tidak Cemas & 33 & 52,4 \\
\hline & Jumlah & $\mathbf{6 3}$ & $\mathbf{1 0 0}$
\end{tabular}

\section{Hasil Bivariat}

Tabel 2 Hubungan variabel Independen dengan variabel Dependen

\begin{tabular}{|c|c|c|c|c|c|c|c|c|c|}
\hline \multirow{3}{*}{ No } & \multirow{3}{*}{ Variabel } & \multicolumn{4}{|c|}{ Insomnia } & & & \multirow{3}{*}{$p$ value } & \multirow{3}{*}{ OR } \\
\hline & & \multicolumn{2}{|c|}{ Ya } & \multicolumn{2}{|c|}{ Tidak } & \multicolumn{2}{|c|}{ Total } & & \\
\hline & & $\mathbf{N}$ & $\%$ & $\mathbf{n}$ & $\%$ & $\mathbf{n}$ & $\%$ & & \\
\hline & \multicolumn{9}{|c|}{ Respon Terhadap Penyakit } \\
\hline \multirow[t]{3}{*}{1} & Sakit & 25 & 92,6 & 2 & 7,4 & 27 & 100 & \multirow{3}{*}{0,000} & \multirow{3}{*}{25.000} \\
\hline & Tidak Sakit & 12 & 33,3 & 24 & 66,7 & 36 & 100 & & \\
\hline & Jumlah & 37 & 58,7 & 26 & 41,3 & 63 & 100 & & \\
\hline \multirow[t]{4}{*}{2} & Gaya Hidup & & & & & & & \multirow{4}{*}{0,000} & \\
\hline & Tidak baik & 27 & 81,8 & 6 & 18,2 & 33 & 100 & & \multirow{3}{*}{9,000} \\
\hline & Baik & 10 & 33,3 & 20 & 66,7 & 30 & 100 & & \\
\hline & Jumlah & 37 & 58,7 & 26 & 41,4 & 63 & 100 & & \\
\hline \multirow[t]{4}{*}{3} & Tingkat Kecemasan & & & & & & & \multirow{4}{*}{0,003} & \multirow{4}{*}{6,154} \\
\hline & Cemas & 24 & 80,0 & 6 & 20,0 & 30 & 100 & & \\
\hline & Tidak cemas & 13 & 39,4 & 20 & 60,6 & 33 & 100 & & \\
\hline & Jumlah & 37 & 58,7 & 26 & 41,3 & 63 & 100 & & \\
\hline
\end{tabular}

\section{Pembahasan}

1. Hubungan Respon Terhadap Penyakit dengan Insomnia pada Wanita Menopause

Berdasarkan hasil uji statistik pada tabel 5.8 di dapatkan $p$ value $=0.000$ yang artinya ada hubungan antara respon terhadap penyakit dengan insomnia pada wanita menopause di Wilayah Kerja Puskesmas Punti Kayu Palembang. Hasil Odds Ratio diperoleh nilai 9.000 yang berarti bahwa wanita menopause yang memiliki gaya hidup tidak baik beresiko
9 kali mengalami insomnia dibandingkan dengan wanita menopause dengan gaya hidup baik.

Faktor penyakit dan nyeri yang diderita oleh lansia merupakan faktor penting yang dapat mempengaruhi kualitas tidur lansia. Hal ini dikarenakan setiap penyakit yang menyebabkan nyeri, ketidak nyamanan fisik, atau masalah suasana hati dapat menyebabkan masalah tidur seperti 
kesulitan tidur atau kesulitan untuk tetap tertidur (Simonson et al, 2007).

Hasil penelitian ini selaras dengan teori Simonson et al (2007) yang menyatakan bahwa lansia yang berusia 55-84 tahun dengan beberapa penyakit lebih mungkin melaporkan kejadian insomnia. Azizah (2011) juga menyatakan bahwa proses penuaan akan meningkatkan kemungkinan terserang penyakit bahkan kematian.

Penelitian ini sejalan dengan penelitian yang dilakukan oleh Irwina (2012). Hasil uji statistik didapatkan $\mathrm{p}$ value $<\alpha$ $(0,0005<0,05)$, berarti pada tingkat kepercayaan $95 \%$ terlihat ada perbedaan ratarata kualitas tidur yang buruk antara lansia yang tidak sakit dengan lansia yang sakit. Peneliti berasumsi bahwa lansia yang tidak sakit hanya akan mengalami insomnia ringan dikarenakan kurangnya gangguan saat tidur seperti nyeri yang dirasakannya

2. Hubungan Gaya Hidup dengan Insomnia pada Wanita Menopause

Berdasarkan hasil uji statistik pada tabel 5.9 didapatkan $p$ value $=0.000$ yang artiya ada hubungan antara gaya hidup dengan insomnia pada wanita menopause di Wilayah Kerja Puskesmas Punti Kayu Palembang. Hasil Odds Ratio diperoleh nilai 9.000 yang berarti bahwa wanita menopause yang memiliki gaya hidup tidak baik beresiko 9 kali mengalami insomnia dibandingkan dengan wanita menopause dengan gaya hidup baik.

Gaya hidup yang tidak sehat juga dapat memicu terjadinya insomnia. Kebiasan mengonsumsi alkohol, rokok, kopi (kafein), obat penurun berat badan, jam kerja tidak teratur, juga dapat menjadi faktor penyebab sulit tidur (Susilo dan Wulandari, 2011).

Hasil penelitian ini sejalan dengan teori Rafknowledge (dalam Ernawati, 2009) yang mengemukakan bahwa individu yang merokok memerlukan waktu dua kali lebih banyak untuk bisa tidur dan lebih sering terbangun dibandingkan dengan individu yang tidak merokok. Selain itu lansia lebih sensitif terhadap kopi, dimana mengkonsumsi kopi 2 gelas atau lebih akan menyebabkan penurunan dari total jumlah waktu tidur sebanyak 2 jam dan peningkatan jumlah waktu yang dibutuhkan untuk jatuh tidur, biasanya dihitung dalam menit.

Hasil penelitian ini didukung oleh penelitian yang dilakukan oleh Hasan Basri Nasution (2016) menyatakan bahwa terdapat hubungan yang bermakna antara gaya hidup dengan kejadian insomnia pada lansia di Kelurahan Andalas wilayah kerja Puskesmas Andalas Padang Tahun 2015 dengan nilai $\mathrm{p}=$ 0,032 yang berarti $p<0,05$.

Peneliti berasumsi jika wanita menopause yang memiliki gaya hidup baik akan lebih tidak berpotensi mengalami insomnia dikarenakan wanita menopause yang memiliki gaya hidup baik akan menghindari mengkonsumsi alcohol, rokok ataupun kafein yang dapat menjadi pemicu sulit tidur yang akan menyebabkan terjadinya insomnia berat.

3. Hubungan Tingkat Kecemasan dengan Insomnia pada Wanita Menopause

Berdasarkan hasil uji statistik pada tabel 5.10 didapatkan $p$ value $=0.003$ yang artinya ada hubungan antara tingkat kecemasan dengan insomnia pada wanita menopause di Wilayah Kerja Puskesmas Punti Kayu Palembang. Hasil Odds Ratio diperoleh nilai 6.154 yang berarti bahwa wanita menopause yang memiliki tingkat kecemasan lebih bersiko 6 kali mengalami insomnia dari pada yang tidak mengalami kecemasan.

Masalah insomnia atau susah tidur akan dialami oleh beberapa lansia seperti pada wanita menopause. Wanita menopause akan terbangun pada malam hari dan sulit untuk bisa tidur kembali. Selain itu juga kesulitan tidur disebabkan karena rendahnya kadar serotonin yang dipengaruhi pada masa pre menopause. Dimana kadar serotonin dipengaruhi oleh kadar endofrin. Serotonin mempengaruhi suasana hati seseorang, jika kadar dalam tubuh menurun, hal ini akan menyebabkan depresi dan sulit tidur. Terjadinya kekhawatiran-kekhawatiran, ketakutan, kecemasan pada masa menopause dapat menyebabkan insomnia (Mulyani, 2013).

Menurut Hawari (2013) gangguan kecemasan merupakan kondisi yang paling umum pada lansia. Lansia menghadapi pikiran kematian dengan rasa putus asa dan kecemasan menjadi masalah psikologis yang pentng pada lansia, khususnya lansia yang mengalami penyakit kronis. Perilaku cemas pada lansia dapat disebabkan oleh penyakit medis fisiologi yang sulit diatasi, kehilangan pasangan hidup, pekerjaan, keluarga dukungan sosial, respons yang berlebihan terhadap kejadian hidup, pemikiran akan datangnya kematian.

Adanya hubungan tingkat kecemasan dengan tingkat insomnia sesuai dengan 
pernyataan Prayitno (2004) yang menyatakan bahwa salah satu faktor yang mempengaruhi insomnia pada lansia adalah kecemasan atau stress.

Penelitian ini sejalan dengan penelitian yang dilakukan Karmila (2015) menunjukkan ada hubungan tingkat kecemasan dengan kejadian insomnia pada lansia ( $p$ value $=0,004)$. Penelitian yang dilakukan sebelumnya oleh Priska Yola (2016), menunjukkan hasil yang significant antara tingkat kecemasan dengan derajat insomnia pada lansia di Posyandu Lansia Mojo Surabaya $(\mathrm{p}=0,000)$.

Penelitian ini sejalan dengan penelitian Riska Dyah (2020) yang menunjukkan terdapat hubungan yang signifikan antara hubungan tingkat kecemasan dengan kejadian insomnia pada lansia di BPSTW Unit Budi Luhur Kasongan Bantul Yogyakarta dengan hasil yang signifikan yaitu $p$ value $=0,012$.

Hasil penelitian ini didukung oleh penelitian yang dilakukan oleh Rodyan (2017) hasil uji statistik didapatkan bahwa $p$ value $0,002<0,05$ menunjukkan bahwa ada hubungan antara tingkat kecemasan dengan kejadian insomnia pada lansia di PKM Bawangan.

Peneliti berasumsi bahwa wanita yang telah memasuki usia menopause akan mudah sulit untuk tertidur dikarenakan adanya kecemasan seperti takut akan kematian dan merasa hidup sendirian.

\section{KESIMPULAN DAN SARAN \\ Kesimpulan}

1. Ada hubungan respon terhadap penyakit dengan kejadian insomnia pada wanita menopause di Posyandu Wilayah Kerja Puskesmas Punti Kayu Tahun 2021 ( $p$ value $=0.000$ ).

2. Ada hubungan gaya hidup dengan kejadian insomnia pada wanita menopause di
Posyandu Wilayah Kerja Puskesmas Punti Kayu Tahun 2021 ( $p$ value $=0.000$ ).

3. Ada hubungan tingkat kecemasan dengan kejadian insomnia pada wanita menopause di Posyandu Wilayah Kerja Puskesmas Punti Kayu Tahun 2021 ( $p$ value $=0,003)$.

\section{Saran}

\section{Bagi Puskesmas}

Diharapkan petugas Puskesmas untuk lebih banyak memberikan informasi, konseling dan mamaksimalkan posyandu lansia agara wanita menopause yang mengalami insomnia dapat segera ditanggani sebaik mungkin.

\section{Bagi Institusi Pendidikan}

Institusi pendidikan lebih memberikan dukungan berupa penyediaan referensi maupun fasilitas yang mendukung penelitian yang lebih lengkap mengenai berbagai ilmu kesehatan yang berkembang sangat pesat.

\section{Bagi Masyarakat}

Wanita menopause sebaiknya mempertahankan kondisi kesehatan fisik, mental yang baik, serta gaya hidup yang sehat. Dukungan keluarga yang meliputi dukungan instrumental, informasi, emosional, dan penilaian sebaiknya dapat lebih ditingkatkan. Keluarga juga dapat mengingatkan kepada wanita menopause/lansia untuk mempertahankan gaya hidup yang sehat seperti mengurangi kebiasaan minum kopi yang berlebihan dan mengingatkan untuk rutin memeriksakan kondisi kesehatannya di posyandu lansia dan pelayanan kesehatan lainnya.

\section{Bagi Peneliti yang Akan Datang}

Penelitian faktor yang berhubungan dengan kejadian insomnia pada wanita menopause ini dilakukan pada wanita menopause yang kunjungan di posyandu wilayah kerja puskesmas sehingga perlu adanya penelitian lebih lanjut pada lansia yang tinggal di insitusi. Peneliti juga menyarankan pada penelitian selanjutnya untuk melakukan analisa data secara multivariat agar dapat diketahui faktor yang paling berpengaruh terhadap kejadian insomnia pada wanita menopause/lansia.

\section{DAFTAR PUSTAKA}


Amalia Senja. (2019). Perawatan Lansia Oleh Keluarga dan Care Giver. Bumi Medika: Jakarta

Alvis Kurniawan, et al. (2020). Pengaruh Senam Lansia Terhadap Penurunan Skala Insomnia Pada Lansia di Desa Batu Belah Wilayah Kerja Puskesmas Kampar Tahun 2020. Jurnal Ners. Vol. 4 No. 2, pp 102-106

Azizah, Lilik Ma'rifatul. (2011). Keperawatan Lanjut Usia. Graha Ilmu: Yogyakarta

Badan Statistik. (2015). http://www.p2ptm.kemkes.go.id/kegiatanp2ptm/aceh/populasi-lansia-diperkirakanterus-meningkat-hingga-tahun-2020. diakeses pada hari Minggu Tanggal 13 Juni 2021

Abu Bakar, Sukawati. (2014). Kesehatan Reproduksi dan Keluarga Berencana dalam Tanya Jawab. Rajawali Pers: Jakarta

Cahya R, Desta A. (2019). Buku ajar Kesehatan Reproduksi Remaja dan Wanita. PT. Pustaka Baru: Yogyakarta

Desi Natalia Trijayanti Idris, et al. (2015). Gambaran Kejadian Insomnia pada Wanita Menopause Berdasarkan Komponen Insomnia Rating Scale. STIKES RS. Baptis: Kediri

Dewinny. Emielda. (2019). Psikologi Kebidanan: Memahami Psikis Wanita Sepanjang Daur Kehidupan dalam Pelayanan Kebidanan. Pustaka Baru Press: Yogyakarta

Dhaval Patel. MD, et al. (2018). Insomnia in The Elderly: A Review: Jurnal of clinical Sleep Medicine

Dinas Kesehatan Kota Palembang. (2018). Profil Kesehatan Tahun 2018: Palembang

Djunizar Djamaludin. (2019). Pengaruh senam Lansia Terhadap Kualitas Tidur Penderita Hipertensi Pada Lansia. Malahayati Nursing Journal. Vol. 1 No 2, pp 217-226

Dyah Riska, Arita. (2020). Hubungan Tingkat Kecemasan dengan Kejadian Insomnia pada Lansia di BPSTW Unit Budi Luhur Kasongan Bantul Yogyakarta. Jurnal Keperawatan. Vol: 9 No.1, pp 1-8

Egeria DS, et al. (2020). Pengaruh Senam Lansia Terhadap Kualitas Tidur Lansia Yang Mengalami Insomnia di Asrama Pemadam Kebakaran. Jurnal Akademi Keperawatan Husada Karya Jaya. Vol. 6 No. 2

Ernawati. (2009). Faktor-Faktor yang Berhubungan dengan Terjadinya Insomnia pada Lanjut Usia di Desa Gayam Kecamatan Sukoharjo Kabupaten Sukoharjo. [Skripsi]. Universitas Muhammadiyah Surakarta.
Erwani. Nofriandi. (2017). Faktor-faktor Yang Berhubungan Dengan Insomnia pada Lansia di Puskesmas Belimbing Padang: Jurnal Ilmu Kesehatan: Padang

Evi Rianjani, Heryanto Adi Nugroho. (2011). Kejadian Insomnia Berdasarkan Karakteristik dan Tingkat Kecemasan pada Lansia di panti Wredha Pucang Gading Semarang. Fikkes Jurnal keperawatan: Semarang

Famelia Yurintika, at al. (2015). Pengaruh Senam Lansia Terhadap Kualitas Tidur Pada Lansia Yang Insomnia. JOM. Vol. 2 No. 2, pp 1116-1122

Ghaddafi Muammar. (2017). Tatalaksana Insomnia dengan Farmakologi atau NonFarmakologi: SMF Ilmu Psikiatri Fakultas Kedokteran Universitas Udayana

Hartono. Dudi, at al. (2019). Penyakit Fisik dan Lingkungan Terhadap Insomnia Bagi Lanjut Usia. Jurnal Kesehatan. Vol. 13 No. 1, pp 1-4

Hasan Basri Nasution. (2016). Faktor-faktor yang Mempengaruhi Terjadinya Insomnia pada Lansia di Samanhudi Kelurahan Estate Kecamatan Binjai Selatan Tahun 2016. Jurnal Riset Hesti Medan. Vol. 1 No. 2, pp 77-83

I Nengah Sumirta. (2016). Faktor Yang Menyebabkan Gangguan Tidur (Insomnia) Pada Lansia: Jurnal Keperawatan Politeknik Kesehatan Denpasar

Ika Fitria Ayuningtyas. (2019). Kebidanan Komplementer Terapi Komplementer dalam kebidanan. Pustaka Baru Press: Yogyakarta

Imelda Fitri. (2017). Lebih Dekat dengan Sistem Reproduksi Wanita. Gosyen Publishing: Yogyakarta

Karmila. (2015). Hubungan Tingkat Kecemasan Dengan Kejadian Insomnia pada Lansia Di RT 001 RW 02 Kelurahan Pangkalan Jati Kecamatan Cinere Kota Depok 2015. [Skripsi]. Universitas Pembangunan Nasional "Veteran"Jakarta.

Kementerian Kesehatan Republik Indonesia. (2019).

https://www.kemkes.go.id/article/print/190 70500004/indonesia-masuki-periode-agingpopulation.html. di akses pada hari Minggu Tanggal 13 Juni 2021

Luo J, et al. (2013). Prevalence and risk factors of por sleep quality among chines elderly in an urban community: results from the Shanghai Aging Study. PloS ONE. Vol 8 No II 
Maisharoh. Rizka. (2020). Faktor-faktor yang Mempengaruhi Kejadian Insomnia pada Lansia di Wilayah Kerja Puskesmas Patikraja Kabupaten Banyumas. Jurnal Keperawatan Muhammadiyah.

Meida Rarasta. Djunaidi AR. (2018). Prevalensi Insomnia pada Usia Lanjut Warga Panti Werdha Dharma Bakti dan Tresna Werdha Teratai Palembang. Biomedical Journal of Indonesia. Palembang

Meril VM, at al. (2011). Pengaruh Senam Lansia Terhadap Keseimbangan Tubuh Pada Lansia di Lingkungan Dajan Bingin Sading. Jurnal Keperawatan COPING NERS

Mulyani S. (2013). Menopause Akhir Siklus Menstruasi Pada Wanita di Usia Pertengahan. Yogyakarta: Nuha Medika.

Ni Wayan, et al. (2020). Hubungan Antara Senam Lansia dan Kualitas Tidur Lansia di Kabupaten Badung. Sport and Fitness Journal. Vol.8 No.3, pp 158-163

Nislawaty. (2017). Pengaruh Senam Lansia Terhadap Kualitas Tidur Pada Lansia di Pelayanan Sosial Tresna Werdha Khusnul Khotimah Kelurahan Simpang Tiga Pekanbaru Tahun 2016. PREPOTIF Jurnal Kesehatan Masyarakat. Vol.1 No.1, pp 5869

Nugroho. (2010). Keperawatan Gerontik dan Geriatrik. Buku Kedokteran EGC: Jakarta

Prayitno. (2004). Psikologi social. Refika Aditama; Bandung

Profil Puskesmas Punti Kayu Palembang Tahun 2020

Ratnawati Ana. (2018). Asuhan Keperawatan pada Pasien dengan Gangguan Sistem Reproduksi. Pustaka Baru Press: Yogyakarta

Rezita Rahma Reza, et al. (2019). Fungsi Tidur dalam Manajemen Kesehatan. Majority: Lampung

Rodiyah. (2017). Hubungan Antara Tingkat Kecemasan dengan Kejadian Insomnia pada Lansia di Puskesmas Bawangan Kabupaten Jombang. Nursing Journal of STIKES Insan Cendekia Medika Jombang. Vo. 14 No. 1, pp 13-19

Simonson, Bergeron, Crecelius, Maguire, Osterweil, Spivack, Stwalley, dan Zee.2007. Improving sleep management in elderly: a guide to the management ofinsomnia in long-term care. Annals of
Long Term Care: Clinical Care andAging 2007;15(12;suppl 1):1-16 [serial online].http://www.annalsoflongtermcare.c om/attachments/12_07_Takeda_ALTC12_ SuppFinalV2.pdf [2 Maret 2012].

Sri Juliani, et al. (2020). Efektivitas Senam Lansia Terhadap Penurunan Tingkat Insomnia di Poskesdes Hutasoit Kecamatan Lintongnihuta Kabupaten Humbang Hasundutan. Gentle Birth. Vol. 3 No. 2, pp $59-70$

Wahyu Ningsih. Ajeng. (2018). Faktor-faktor yang Mempengaruhi Kejadian Insomnia Pada Lansia di Posyandu Lansia Wilayah Kerja UPTD Puskesmas Puncu Kabupaten Kediri. Jurnal Ilmu Kesehatan. Vol. 9 No.1, pp 66-74

Wulandari dan Susilo. (2011). Cara Jitu Mengatasi Insomni.Yogyakarta: Penerbit CV Andi Offset

Yhenti Widjayanti. (2017). Gambaran Kualitas Tidur Wanita Menopause. Jurnal Keperawatan. Vol. X No 1, pp 1-5. Surabaya 